Louisiana State University

LSU Digital Commons

5-7-2013

\title{
Magnetic properties and phase transitions of gadolinium-infused carbon nanotubes
}

\author{
Abdiel Quetz \\ Southern Illinois University Carbondale \\ Igor Dubenko \\ Southern Illinois University Carbondale \\ Tapas Samanta \\ Southern Illinois University Carbondale \\ Herbert Vinson \\ Southern Illinois University Carbondale \\ Saikat Talapatra \\ Southern Illinois University Carbondale
}

See next page for additional authors

Follow this and additional works at: https://digitalcommons.Isu.edu/physics_astronomy_pubs

\section{Recommended Citation}

Quetz, A., Dubenko, I., Samanta, T., Vinson, H., Talapatra, S., Ali, N., \& Stadler, S. (2013). Magnetic properties and phase transitions of gadolinium-infused carbon nanotubes. Journal of Applied Physics, 113 (17) https://doi.org/10.1063/1.4796151

This Conference Proceeding is brought to you for free and open access by the Department of Physics \& Astronomy at LSU Digital Commons. It has been accepted for inclusion in Faculty Publications by an authorized administrator of LSU Digital Commons. For more information, please contact ir@lsu.edu. 


\section{Authors}

Abdiel Quetz, Igor Dubenko, Tapas Samanta, Herbert Vinson, Saikat Talapatra, Naushad Ali, and Shane Stadler 
Southern Illinois University Carbondale

OpenSIUC

Publications

Department of Physics

$5-2013$

\title{
Magnetic Properties and Phase Transitions of Gadolinium-infused Carbon Nanotubes
}

\author{
Abdiel Quetz \\ Southern Illinois University Carbondale \\ Igor Dubenko \\ Southern Illinois University Carbondale \\ Tampas Samanta \\ Southern Illinois University Carbondale \\ Herbert Vinson \\ Saikat Talapatra \\ See next page for additional authors
}

Follow this and additional works at: http://opensiuc.lib.siu.edu/phys_pubs

(C) 2013 American Institute of Physics

Published in Journal of Applied Physics Vol. 113 No. 17B512 (2013) at doi: 10.1063/1.4796151

\section{Recommended Citation}

Quetz, Abdiel, Dubenko, Igor, Samanta, Tampas, Vinson, Herbert, Talapatra, Saikat, Ali, Naushad and Stadler, Shane. "Magnetic Properties and Phase Transitions of Gadolinium-infused Carbon Nanotubes." (May 2013).

This Article is brought to you for free and open access by the Department of Physics at OpenSIUC. It has been accepted for inclusion in Publications by an authorized administrator of OpenSIUC. For more information, please contact opensiuc@lib.siu.edu. 
Authors

Abdiel Quetz, Igor Dubenko, Tampas Samanta, Herbert Vinson, Saikat Talapatra, Naushad Ali, and Shane Stadler 


\title{
Magnetic properties and phase transitions of gadolinium-infused carbon nanotubes
}

\author{
Abdiel Quetz, ${ }^{1, a)}$ Igor Dubenko, ${ }^{1}$ Tapas Samanta, ${ }^{1}$ Herbert Vinson, ${ }^{1}$ Saikat Talapatra, ${ }^{1}$ \\ Naushad Ali, ${ }^{1}$ and Shane Stadler ${ }^{2}$ \\ ${ }^{1}$ Department of Physics, Southern Illinois University at Carbondale, Carbondale, Illinois 92901, USA \\ ${ }^{2}$ Department of Physics \& Astronomy, Louisiana State University, Baton Rouge, Louisiana 70803, USA
}

(Presented 16 January 2013; received 5 November 2012; accepted 19 December 2012; published online 25 March 2013)

\begin{abstract}
Carbon nanotube (CNT)/metal-cluster-based composites are envisioned as new materials that possess unique electronic properties which may be utilized in a variety of future applications. Superparamagnetic behavior was reported for CNTs with Gd ions introduced into the CNT openings by internal loading with an aqueous $\mathrm{GdCl}_{3}$ chemical process. In the current work, the magnetic properties of the CNT/Gd composites were obtained by the joining and annealing of Gd metal and CNTs at $850^{\circ} \mathrm{C}$ for $48 \mathrm{~h}$. Energy dispersive X-ray analysis shows the presence of Gd intermingled with the CNT walls with maximum and average Gd concentrations of about $20 \%$ and $4 \%$ (by weight), respectively. The Gd clusters have a non-uniform distribution and are mostly concentrated at the ends of the CNTs. A ferromagnetic-type transition at $\mathrm{T}_{\mathrm{C}} \sim 320 \mathrm{~K}$, accompanied by jump like change in magnetization and temperature hysteresis typical for the temperature induced first order phase transitions has been observed by magnetization measurements. It was found that $\mathrm{Gd}$ infused into the CNTs by the annealing results in a first order paramagnetic-ferromagnetic transition at $\mathrm{T}_{\mathrm{C}}=320 \mathrm{~K}$. $@ 2013$ American Institute of Physics. [http://dx.doi.org/10.1063/1.4796151]
\end{abstract}

\section{INTRODUCTION}

Nanocomposite magnetic materials have the advantage of acquiring singular magnetic properties that are not normally observed in other materials. These magnetic materials have unlocked a new path of opportunities in the technological and medical disciplines; they have potentially provided new measurement methods and medical procedures that may be utilized in a variety of current and future applications. ${ }^{1} \mathrm{~A}$ new property of materials in which our study finds its background, is the superparamagnetic behavior of carbon nanotubes (CNTs) produced when Gd ions are introduced into the CNT's openings by internal loading with an aqueous $\mathrm{GdCl}_{3}$ chemical process. These molecular magnets are used as contrast agents in magnetic resonance imaging, and have shown an efficacy 40 to 90 times larger than any other $\mathrm{Gd}^{3+}$-based contrast agent. ${ }^{2,5,6}$ The maximum magnetic moment of gadolinium is $7 \mu_{\mathrm{B}}$ which is about two times larger than those of the $3 \mathrm{~d}$ metals $\mathrm{Fe}, \mathrm{Ni}$, and Co. Therefore, molecular magnets based on Gd metal are expected to show enhanced magnetoresponsive properties relative to those based on $3 \mathrm{~d}$-metals. However, the introduction of Gd-based compounds into carbon nanotubes using an aqueous chemical process results in paramagnetic/superparamagnetic behavior of the composites [see Ref. 2 as an example], resulting in a limited range of application that depends on the nature of the magnetic order of the composites. In the current work, the magnetic properties of the CNT/Gd composites were obtained as a result of the joining and annealing of Gd metal (99.9\% of purity) and CNTs at $850^{\circ} \mathrm{C}$ for $48 \mathrm{~h}$, which is an innovative method to

\footnotetext{
a) Author to whom correspondence should be addressed. Electronic mail: anorve2002@yahoo.com.
}

achieve the discussed outcome of merged Gd atoms into the CNTs by diffusion. The phase transition to a ferromagneticlike state at about $320 \mathrm{~K}$ has been detected for the CNT-Gd composite.

\section{EXPERIMENTAL DETAILS}

The carbon nanotubes were synthesized by an airassisted chemical vapor deposition technique ${ }^{3}$ and detached mechanically from aluminum substrate. To transfer Gd ions into CNTs, we followed the diffusion process. The Gd fragments of $99.99 \%$ purity were joined together to form a single ingot under an ultra-high pure argon atmosphere in an arc-melting furnace. Subsequently, the ingot was placed in a diamond saw and cut in half, forming two plates of high purity $\mathrm{Gd}$; the CNTs were placed between the two Gd plates forming a sandwich-like Gd-CNT-Gd structure and annealed under high vacuum $\left(\approx 10^{-5}\right.$ Torr $)$ for a time period of $48 \mathrm{~h}$ at a constant temperature of $850^{\circ} \mathrm{C}$. The Gd-CNT composite was characterized with field emission scanning electron microscopy (FESEM, Quanta FEI 450 D 9506), with elemental analysis capabilities using energy dispersive $\mathrm{x}$-ray analysis (EDAX). The concentration of Gd intermingled within the CNT's walls was determined using the EDAX available in the FESEM. Thermo-magnetic measurements have been performed with a super conducting quantum interference device magnetometer (SQUID, Quantum Design) in the temperature interval $(5-400 \mathrm{~K})$ and magnetic fields up to $20 \mathrm{kOe}$. The magnetization curves $\mathrm{M}(\mathrm{T})$ have been measured during the heating and cooling cycles after the sample has been cooled down from $380 \mathrm{~K}$ to $5 \mathrm{~K}$ at zero magnetic field (zero-field-cooled (ZFC)) and start from $380 \mathrm{~K}$, respectively, at magnetic fields $500 \mathrm{Oe}$ and $20 \mathrm{kOe}$. 

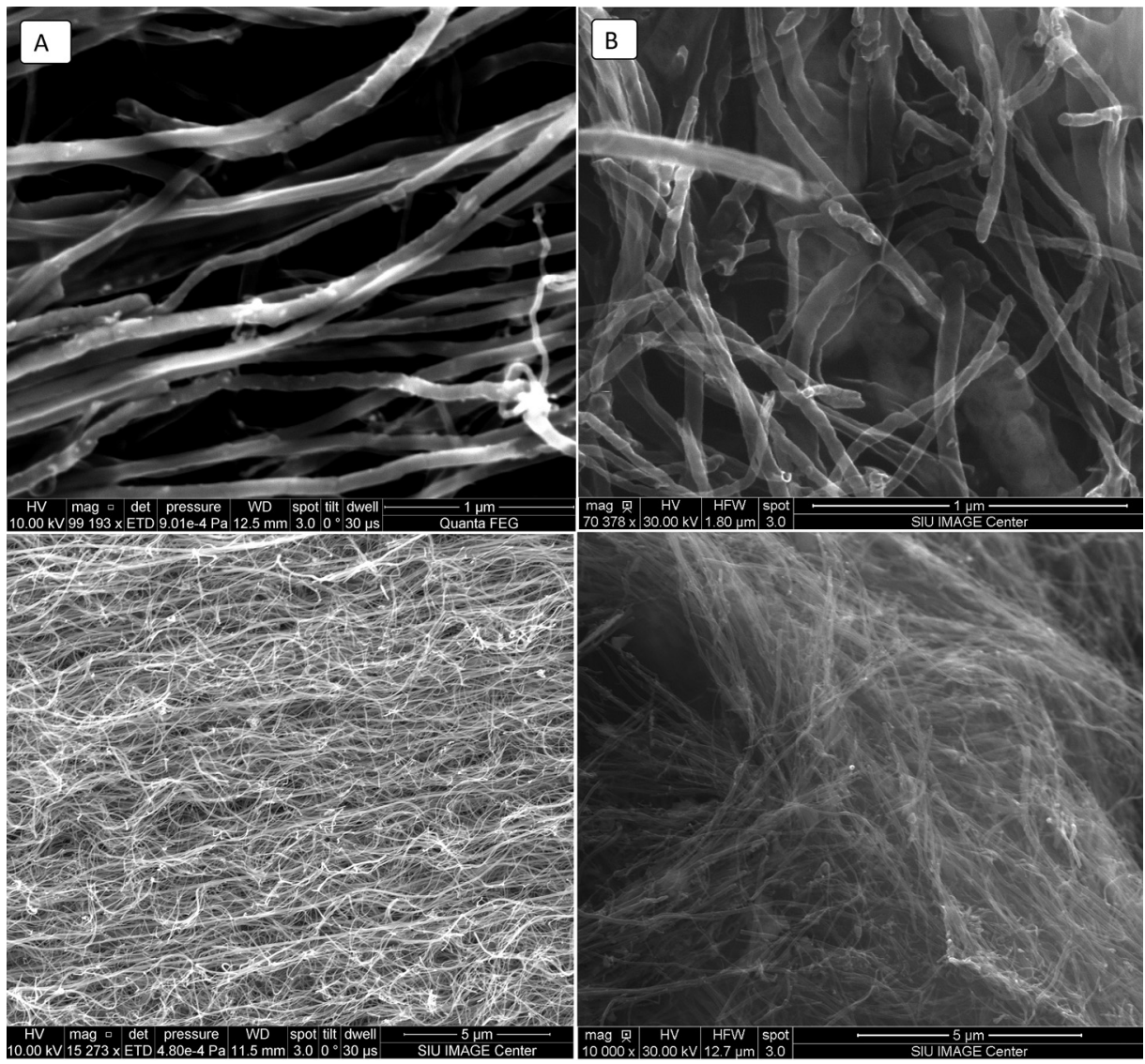

FIG. 1. SEM images of CNT without Gd (a) and $\mathrm{CNT}+\mathrm{Gd}(\mathrm{b})$.
TABLE I. EDAX elemental analysis at $20 \mu \mathrm{m}$.

\begin{tabular}{lcc}
\hline \hline Element & Wt. \% & At. \% \\
\hline $\mathrm{C}$ & 75.65 & 83.27 \\
$\mathrm{O}$ & 19.71 & 16.29 \\
$\mathrm{Cl}$ & 0.05 & 0.02 \\
$\mathrm{Fe}$ & 0.07 & 0.02 \\
$\mathrm{Cu}$ & 0.07 & 0.01 \\
$\mathrm{Zn}$ & 0.18 & 0.04 \\
$\mathrm{Ge}$ & 0 & 0 \\
$\mathrm{Gd}$ & 4.28 & 0.36 \\
Total & 100 & \\
\hline \hline
\end{tabular}

\section{EXPERIMENTAL RESULTS AND DISCUSSION}

Figure 1 illustrates the results from the EDAX measurements for both the parent CNTs and CNT+Gd. The heavy metal $(\mathrm{Gd})$ tends to appear in a brighter color since the microscope electrons scatter from the surface. ${ }^{7}$ Referring to Figure 1(a), one can see that the parent CNTs have a visible uniformity in the colors and brightness since the microscope electrons pass through the CNT's surface without being scattered. On the other hand, in Figure 1(b), the CNTs faintly appear due to the EDAX contrast effect, while the areas where Gd has been absorbed by the CNTs appear more pronounced. EDAX analysis verifies that the CNTs contain Gd. ${ }^{4}$

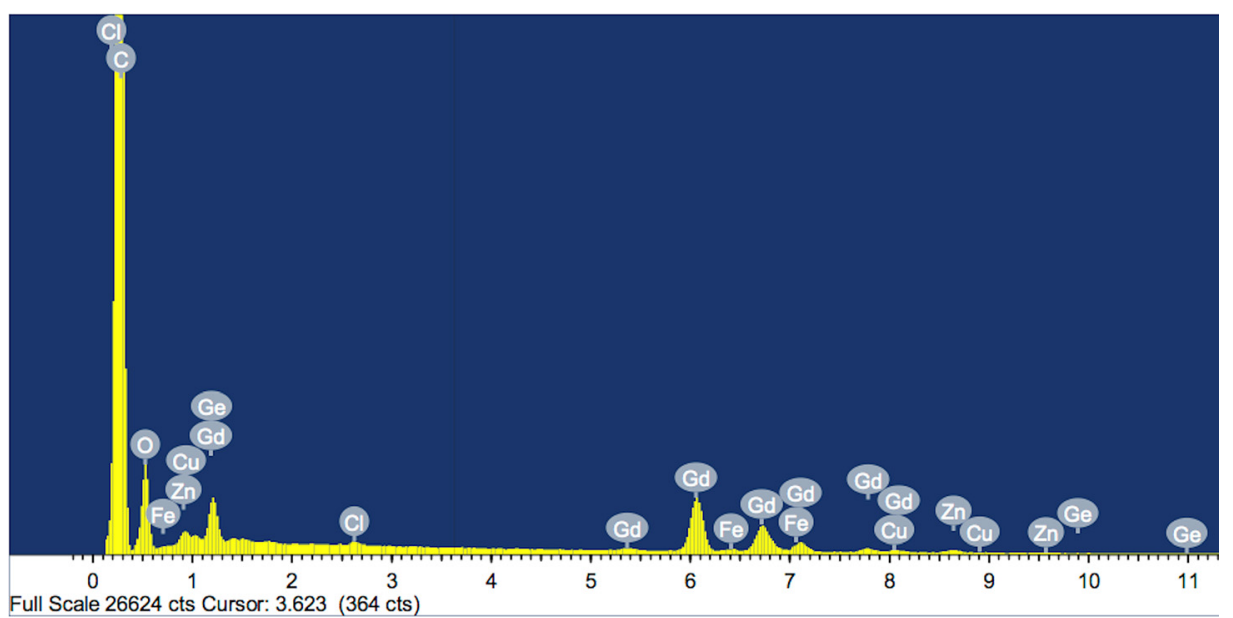

FIG. 2. Example of EDAX microanalysis. 


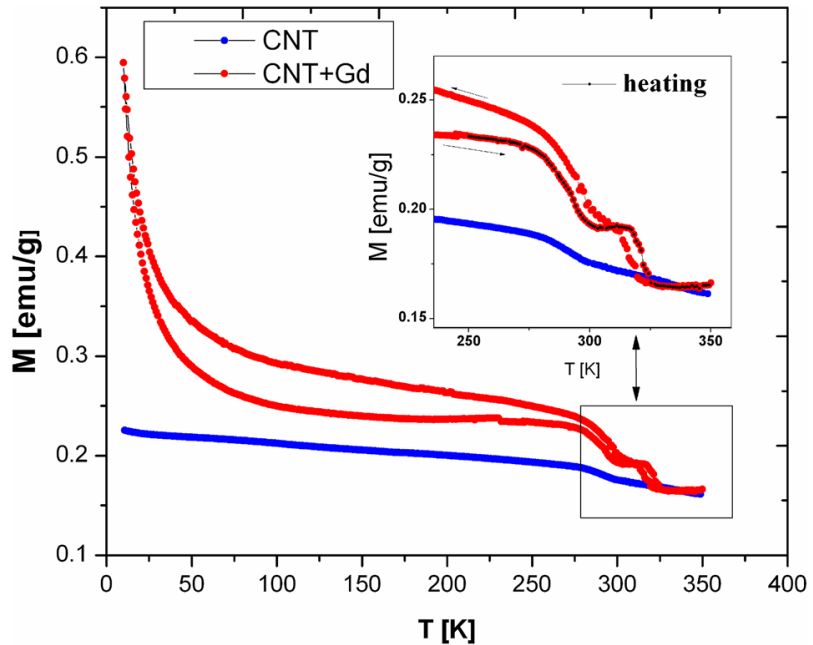

FIG. 3. MvT at $500 \mathrm{G}$ for $\mathrm{CNT}$ and $\mathrm{CNT}+\mathrm{Gd}$.

Results from the EDAX elemental analysis of a $10 \mu \mathrm{m}$ by $20 \mu \mathrm{m}$ window show that Gd is $4.3 \%$ of the CNT/Gd analyzed sample (see Table I and Figure 2). Therefore, some fraction of $\mathrm{Gd}$ atoms has been absorbed by the CNTs, and the Gd atoms basically reside in sites at the tube ends and in defects. These results reflect the similar outcome observed in Ref. 2. As we reduce the dimensions of the window from the EDAX elemental analysis, the percentage of Gd increases, respectively, until it reaches approximately $20 \%$ of the total weight of the impregnated CNT.

The results of the magnetization measurements are shown in Figure 3. The $\mathrm{M}(\mathrm{T})$ curve of CNT shows smooth change in magnetization with respect to the temperature at about $270 \mathrm{~K}$. In the CNT/Gd sample, the behavior of $\mathrm{M}(\mathrm{T})$ shows remarkable changes in the magnetic properties. Two transitions are clearly visible: one at $270 \mathrm{~K}$ and another at $325 \mathrm{~K}$ for $\mathrm{Gd}+\mathrm{CNT}$ sample. The high temperature transition shows a jump like decrease in magnetization with increasing temperature and temperature hysteresis of magnetization $\mathrm{M}(\mathrm{T})$, typical for temperature-induced first order transition from ferromagnetic to paramagnetic states. From the comparison of the M(T) curves obtained for applied magnetic fields $\mathrm{H}=500 \mathrm{G}$ and $20 \mathrm{kG}$ (Figure 4), it is possible to see that $\mathrm{M}(\mathrm{T})$ at $20 \mathrm{kG}$ still shows the jump-like transition at about $320 \mathrm{~K}$ with temperature hysteresis. The transition at $280 \mathrm{~K}$ is "suppressed" by the magnetic field. The suppression is most likely related to the presence of the small amount of magnetic impurities in the sample. In the region where the sample magnetization is far from saturation and the sample is characterized by a large magnetic susceptibility, the contribution from magnetic impurities to the total magnetization becomes undetectable at high applied magnetic fields. Considering that iron has been used as a catalyst for the growth of the CNT samples, and that CNTs contain only a small amount of iron ( 0.07 mass $\%$, see Table I), the transition at $280 \mathrm{~K}$ most likely related to iron based impurities. The maximum magnetic moment of $\mathrm{CNT} / \mathrm{Gd}$ at $\mathrm{T}=10 \mathrm{~K}$ in the applied magnetic field $\mathrm{H}=20 \mathrm{kOe}$ is $6 \mu_{\mathrm{B}} / \mathrm{Gd}$, as estimated from M(T) (see Figure 4) and Gd concentration (see Table I).

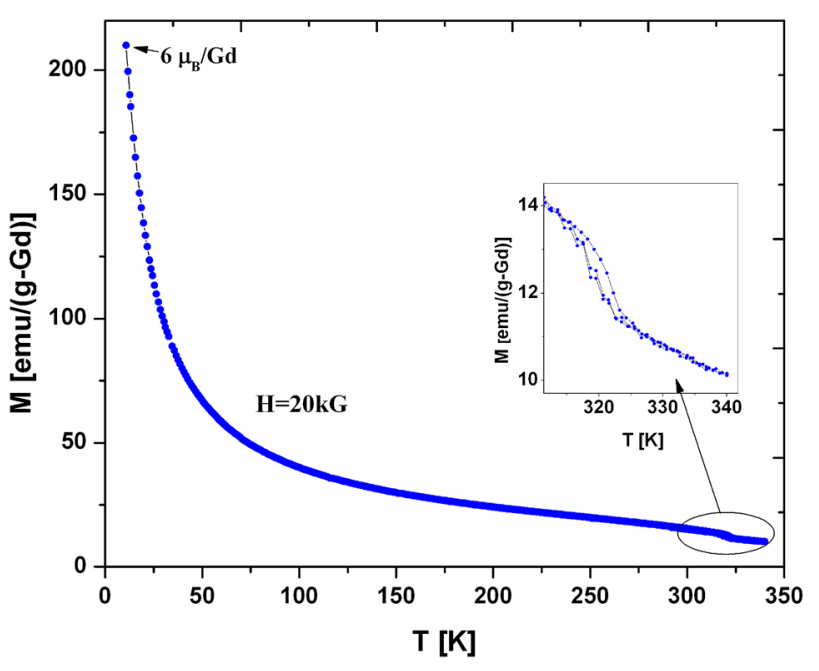

FIG. 4. MvT of CNT-Gd composite obtained at applied magnetic field $\mathrm{H}=20 \mathrm{kG}$ calculated per Gd atom using the results of EDAX analysis (see Table I).

This value is in good agreement with a magnetic moment of $7 \mu_{\mathrm{B}}$ for the $\mathrm{Gd}^{+3}$ ion. $^{2}$

\section{CONCLUSION}

It has been shown that during the annealing of the sandwich-like Gd-CNT-Gd structure for $48 \mathrm{~h}$, Gd ions can penetrate the CNTs up with maximum and average Gd concentration of about $20 \%$ and $4 \%$ (by weight), respectively. The presence of Gd in the CNT can modify the magnetic properties of the CNT and result in a first paramagneticferromagnetic phase transition near room temperature. Therefore, the Gd-CNT composite obtained by the diffusion method of synthesis is a prospective material for future investigations in medical and other technological disciplines.

\section{ACKNOWLEDGMENTS}

This research was supported by the Office of Basic Energy Sciences, Material Science Division of the U.S. Department of Energy (Grant No. DE-FG02-06ER46291). S.T. acknowledges financial support through NSF-ECCS Grant No. 0925682.

${ }^{1}$ J.-C. Charlier, X. Blase, and S. Roche, Rev. Mod. Phys. 79, 677 (2007).

${ }^{2}$ B. Sitharaman, K. R. Kissell, K. B. Hartman, L. A. Tran, A. Baikalov, I. Rusakova, Y. Sun, H. A. Khant, S. J. Ludtke, W. Chiu, S. Laus, É Tóth, L. Helm, A. E. Merbach, and L. J. Wilson, Chem. Commun. (Cambridge) 31, 3915 (2005).

${ }^{3}$ X. Li, X. Zhang, L. Ci, R. Shah, C. Wolfe, S. Kar, S. Talapatra, and P. M. Ajayan, Nanotechnology 19, 455609 (2008).

${ }^{4}$ C. Liang, D. Romero, J. Amaral, and P.-C. Ho, in NCUR, Ithaca College, March 31-April 2, 2011.

${ }^{5}$ M. Ahrén, L. Selegård, A. Klasson et al. Langmuir 26(8), 5753-5762 (2010).

${ }^{6}$ A. Hedlund, M. Ahrén, H. Gustafsson, N. Abrikossova, M. Warntjes, J. I. Jönsson, K. Uvdal, and M. Engström, Nanomedicine 6, 3233-3240 (2011).

${ }^{7}$ S. Parrish, "Contrasting transmission electron microscopy and scanning electron microscopy," Helium Articles Today, retrieved from: http://www.helium.com/items/2381892-contrasting-transmission-electronmicroscopy-and-scanning-electron-microscopy (2012 October 15). 